\title{
Contribuições do Psicólogo Escolar no Processo de Inclusão de Crianças com Dificuldades de Aprendizagem na Escola
}

\author{
Byanca Eugênia Duarte Silva ${ }^{1}$; Henry Witchael Dantas Moreira ${ }^{2}$; Andreia Braga de Oliveira ${ }^{3}$;
} Maria Auxiliadora Lobo Silva ${ }^{4}$; Maria das Graças de Carvalho

\begin{abstract}
Resumo: Este estudo aborda o contexto social da inclusão escolar e objetiva analisar as contribuições da intervenção do psicólogo escolar no processo de inclusão, especificamente dos alunos com dificuldades de aprendizagem, discorrendo sobre a Educação inclusiva, a importância do acolhimento escolar de crianças com dificuldades de aprendizagem. O método consistiu em uma revisão bibliográfica, com abordagem qualitativa, nas bases de dados: Scielo, Pepsic e Google Acadêmico, além de livros e periódicos, seguindo termos norteadores como Inclusão, Dificuldades de Aprendizagem, Atuação do psicólogo escolar, contribuições para a inclusão, entre outras. Os resultados apontaram que a prática de atuação do profissional de Psicologia na escola contribui para vencer o desafio da inclusão, uma vez que o mesmo possui conhecimentos e dominam técnicas favoráveis à relação entre as pessoas, podendo orientar os docentes, ajudar no diagnóstico dos alunos e auxiliar os pais na compreensão das dificuldades. Concluiu-se que a escola inclusiva é uma necessidade para a educação construtivista e democrática, que não prescinde da intervenção do psicólogo escolar, para facilitar a vida dos alunos e o sucesso da instituição.
\end{abstract}

Palavras - Chave: Inclusão. Dificuldade de Aprendizagem. Educação. Escola. Psicólogo Escolar.

\section{The School Psychologist Contributions in the Process of Inclusion of Children with Learning Disabilities}

\begin{abstract}
This study addresses the social context of school inclusion and aims to analyze the contributions of the intervention of the school psychologist in the inclusion process, specifically of the students with learning disabilities, discussing on Inclusive Education, the importance of the school reception of children with difficulties of learning. The method consisted of a bibliographical review, with a qualitative approach, in the databases: Scielo, Pepsic and Google Scholar, as well as books and periodicals, following guiding terms such as Inclusion, Learning Difficulties, School psychologist work, contributions to inclusion, among others. The results showed that the practice of the Psychology professional in the school contributes to overcome the challenge of inclusion, since it has knowledge and master techniques favorable to the relationship between people, being able to guide teachers, help in the diagnosis of students and assist parents in understanding difficulties. It was concluded that inclusive school is a necessity for constructivist and democratic education, which does not ignore the intervention of the school psychologist, to facilitate the life of the students and the success of the institution.
\end{abstract}

Keywords: Inclusion. Learning Difficulty. Education. School. School Psychologist.

\footnotetext{
${ }^{1}$ Psicóloga pela Faculdade Santa Maria. Especialista em Docência do Ensino Superior e em Psicopedagogia Clínica e Institucional. Especializanda em Terapia Cognitivo-comportamental (TCC). Professional Life \& Coach pelo instituto BBC e Facilitadora de grupos; ${ }^{2}$ Fisioterapeuta pela Universidade Federal da Paraíba. Especialista em cardiorrespiratória. Atualmente é fisioterapeuta do Hospital Regional de Cajazeiras e do Município de Santa Helena - PB.

${ }^{3}$ Graduação em Ciências Sociais pela Universidade Federal da Paraíba. Especialização em Psicopedagogia pela Faculdades Integradas de Patos - PB.

${ }^{4}$ Mestrado em Educação pela Unissulivan Inc. Contato: lobosilvamestrado@ outlook.com

${ }^{5}$ Mestrado em Ciências da Educação pela Universidade Lusófona de Humanidades e Tecnologias - ULHT- Lisboa/Portugal; Graduação em História pela Faculdade de Formação de Professores de Araripina-PE - FAFOPA. Especialização em: Metodologia do Ensino Superior(AEDA); Psicopedagogia em Educação (Leão Sampaio) ; Historia e sociologia (URCA)Educação contextualizada no semiárido (UESPI); Politicas Educativas e Docência do Ensino Superior(AEDA); Atualmente: Secretaria Adjunta da secretaria municipal de educação da cidade de Simões - PI; Professora do Centro de Educação Municipal de simões-PI. Contato: grace.arthur@hotmail.com
} 


\section{Introdução}

Tendo em vista o grande número de crianças que apresentam algum tipo de dificuldade de aprendizagem nas salas de aula das escolas brasileiras, das quais algumas já podem ser consideradas distúrbios, faz-se necessário o desenvolvimento deste trabalho com o intuito de se conhecer mais sobre esta realidade, inclusive as circunstâncias que as ocasionam, as consequências para aprendizagem do aluno, as possibilidades de intervenções e as contribuições do psicólogo escolar para promover a inclusão escolar dos alunos que apresentam algum tipo de dificuldade de aprendizagem.

Primeiramente, são mencionadas algumas dificuldades encontradas pelas crianças ao tentar distinguir letras e sons semelhantes, o que afeta diretamente uma boa prática de leitura e, principalmente, o entendimento do texto lido. Neste contexto remete-se a pedagogias que valorizem a inclusão escolar, que agreguem conhecimento coletivamente e respeite as diferenças, tratando todos iguais conforme as particularidades de cada indivíduo.

Posteriormente, serão enfatizadas as dificuldades de aprendizagem de forma ampla, sem especificá-las, detendo-se as possíveis causas que levam a distração ou até mesmo, causas patológicas, que impedem o aluno de acompanhar os conteúdos e desenvolver sua capacidade cognitiva no mesmo ritmo dos demais colegas de sala de aula, prejudicando-se e dificultando o trabalho do docente. Neste viés, em abordagem breve, será discutido a participação e o apoio da família durante as fases da aprendizagem, vendo os pais como personagens principais na aquisição dos primeiros conhecimentos, pois, ao contrário do que muitos pensam, não é na escola que o desenvolvimento se inicia; é dever da família começar a ensinar e educar a criança para que depois, ela possa aprimorá-los em uma instituição de ensino.

Para concluir, a abordagem será pautada na relevância do psicólogo escolar na promoção da inclusão de crianças com Dificuldades de Aprendizagem, apontando a escola como detentora de papel fundamental na construção do saber e formação cidadã de cada indivíduo, sendo esta responsável por acolher e educar todos os indivíduos que a procurem, valorizando o acolhimento de crianças com dificuldades de aprendizagem na Educação dos Anos Iniciais. Assim, considera-se que é primordial o debate de tais temáticas, para agregar informações aos pesquisadores, profissionais e demais interessados pelo tema.

Como método de coleta de dados foi realizada uma pesquisa bibliográfica com abordagem qualitativa, foram realizadas as pesquisas sistematicamente nos parâmetros de busca 
eletrônicas: Scielo, Pepsic e Google Acadêmico, além de livros e periódicos próprios, seguindo termos norteadores como Inclusão, Dificuldades de Aprendizagem, Atuação do psicólogo escolar, contribuições para a inclusão, entre outras.

\section{Princípios da Inclusão Escolar}

Sabe-se que os alunos com e sem dificuldades de aprendizagem, distúrbios ou qualquer diferença ou deficiência que seja que foram e são ainda excluídos das escolas, devem estar inseridos nessas instituições e que isso é previsto por Lei. Se os pais, professores, gestores educacionais e demais profissionais não tinham conhecimento do direito resguardado a todos de uma educação de qualidade, hoje há diversos documentos legais comprobatórios que estão cumprindo o seu dever de alertar os sujeitos da aprendizagem nesse sentido. De acordo com a Lei $\mathrm{n}^{\circ}$ 9.394/96, art. $5^{\circ}$, mencionada na LDB (2014):

\footnotetext{
O acesso à educação básica obrigatória é direito público subjetivo, podendo qualquer cidadão, grupo de cidadãos, associação comunitária, organização sindical, entidade de classe ou outra legalmente constituída e, ainda, o Ministério Público, acionar o poder público para exigi-lo (LEI DE DIRETRIZES E BASE DA EDUCAÇÃO NACIONAL, 2014).
}

Embora as crianças tenham o direito de estar na escola, percebe-se que em algumas ocasiões, algumas delas não conseguem de fato permanecer na escola, por que são compreendidas de uma forma inadequada, por apresentarem dificuldades de aprendizagem ou, até mesmo, algum tipo de distúrbio ou transtorno mais grave.

Compreender o outro, suas potencialidades e valorizar a diversidade como oportunidade de conviver juntos na diferença é um desafio cada vez mais comum nos dias atuais. Incluir na perspectiva de oportunizar igualdade para todos significa reconhecer a importância de cada membro em sala de aula e na sociedade que o constitui como indivíduo ético e propositor de opiniões. Mantoan (2003) corrobora que "As diferenças culturais, sociais, étnicas, religiosas, de gênero, enfim, a diversidade humana está sendo cada vez mais destacada e é condição imprescindível para se entender como compreendemos o mundo e a nós mesmos" (MANTOAN, 2003, p.16).

As dificuldades de aprendizagem são diversas, permitindo uma confusão de ideias no momento de identificá-la. Por isso, os múltiplos olhares em relação à essa realidade não exigem 
padronizações ou expectativas hegemônicas que criem estereótipos para alunos com ou sem DA. Para que ocorra a diferenciação e compreensão das limitações dos sujeitos da aprendizagem, torna-se necessário uma reflexão minuciosa de cada déficit (SANTOS, 2015).

Diante da compreensão das dificuldades de aprendizagem, percebe-se que, em meio às características que as definem, a distração ou falta de atenção durante a execução das atividades, principalmente na leitura, leva alguns educadores a não observarem os déficits que dificultam a construção do conhecimento, já que este está relacionado à capacidade cognitiva e ao desenvolvimento emocional da criança. Logo, no processo educacional o papel de quem ensina e a forma como se aprende são fatores importantíssimos para que professores e alunos criem vínculos indispensáveis para a aprendizagem. Tomar decisões e criar condições para processos democráticos, onde a família possa participar do acompanhamento dos filhos no desenvolver cotidiano de suas habilidades, implica em esclarecer e demonstrar aos parentes que não há nada de anormal com a criança que apresenta dificuldades na escola (SANTOS, 2015).

Este processo inclusivo do qual tanto se fala precisa ser construído de maneira sócio interacionista, pois ensinar e aprender envolve o professor, o aluno e o meio onde se dá a aprendizagem. Para Mártin e Gonzáles-Gil (2011), a inclusão escolar deve ser total:

[...] a Educação Inclusiva parte do princípio que todos os alunos têm direitos: os alunos com incapacidades, os pertencentes a contextos socioculturais desfavorecidos, os imigrantes, os que têm problemas de comportamento, etc..., e evidentemente todos os demais; numa palavra TODOS com suas singularidades pessoais e sociais (MARTÍN; GONZÁLEZ-GIL, 2011, p. 151-152).

A inclusão, portanto, causa uma mudança de perspectiva educacional, pois não se limita a ajudar somente os alunos que apresentam dificuldades de aprendizagem na escola, mas promove a inclusão de crianças com deficiências diversas, transtornos e demais bloqueios, incentiva e apoia os professores, funcionários e pais para que se obtenha sucesso na corrente educativa geral, por meio da luta pelos direitos a educação inclusiva de todos que dela precisam.

Nessa perspectiva, a inclusão deve considerar todos os aspectos do indivíduo como a diversidade de estilos, comportamentos, expressões, abordagens, reações diante do novo e desconhecido, além da estreita relação que cada um têm com o saber. Cada dificuldade limita a compreensão imediata do aluno, mas não tira-lhe a oportunidade de aprendizagem futuramente (SANTOS, 2015). 


\title{
O Acolhimento de Crianças com Dificuldades de Aprendizagem na Escola
}

A relação da criança com a aprendizagem ocorre de maneira natural e espontânea no curso natural da vida, mas pode em alguns casos apresentar dificuldades específicas de aquisição do saber. Tais dificuldades referem-se a um grupo heterogêneo de transtornos que se manifestam por dificuldades significativas na aquisição e uso da apropriação de saberes relativos à leitura, escrita, cálculos matemáticos, raciocínio lógico ou coordenação motora (DÍAZ, 2011).

Denominada por alguns como déficits ou distúrbio de aprendizagem, as dificuldades de aprendizagem podem ocorrer em alunos com talento para a dança, arte, mecânica ou esporte. Nessa perspectiva, deve-se compreender que as crianças com DA não são deficientes, incapazes ou neutralizadas, demonstrando, apenas, dificuldades para aprender. Diz-se que um aluno está com dificuldades de aprendizagem, quando passa a não conseguir compreender corretamente conteúdos expostos, ou desempenhar outras atividades relativas a técnica do decodificar e aprender, independentemente, deste, ter ou não potencial para aprender o que é apresentado cotidianamente no curso natural das aulas em todas as matérias (DÍAZ, 2011).

Estas dificuldades precisam ser notadas, encaminhadas, diagnosticadas e acompanhadas por profissional competente e capacitado para isso, para que o aluno seja compreendido em sua totalidade e o docente repense sua prática pedagógica para a inclusão deste aluno.

\begin{abstract}
As crianças com dificuldades de aprendizagem possuem disfunções em habilidades necessárias para haver aprendizagem efetiva, apresentando problemas na compreensão da leitura, organização e retenção da informação e na interpretação de textos. Geralmente são lentas ao processar informações, apresentam estratégias pobres para escrever, problemas de organização espacial e muita distração o que acarreta dificuldade de comunicação e hábitos ineficientes de estudo (SANTOS, 2015, p.25).
\end{abstract}

A partir desses conhecimentos, torna-se válido apresentar e analisar as principais dificuldades de aprendizagem observadas em algumas crianças no âmbito educacional e que fazem parte do desenvolvimento e maturação desses indivíduos, abrangendo a capacidade real que eles possuem para assimilar e acomodar conhecimento. Essas dificuldades se caracterizam por: dislexia, disgrafia, disortografia, discalculia, dislalia e erros de formulação e sintaxe, e formaliza o grupo dos principais déficits de aprendizagem ligados a estrutura intrínseca do ser, 
uma vez que as dificuldades ligadas a fatores externos ocupam uma gama muito extensa também e devem ser compreendidas como aquelas que abrangem as interferências dos ciclos social, ambiental e familiar do ser (DÍAZ, 2011).

As dificuldades de aprendizagem específicas se destacam em meio às outras porque compõem uma percentagem mais elevada que os outros problemas de aprendizado, possuindo uma prevalência em meio as NEE (Necessidades Educativas Especiais), com uma taxa de prevalência 2 de $48 \%$ - cf. Gráfico 3

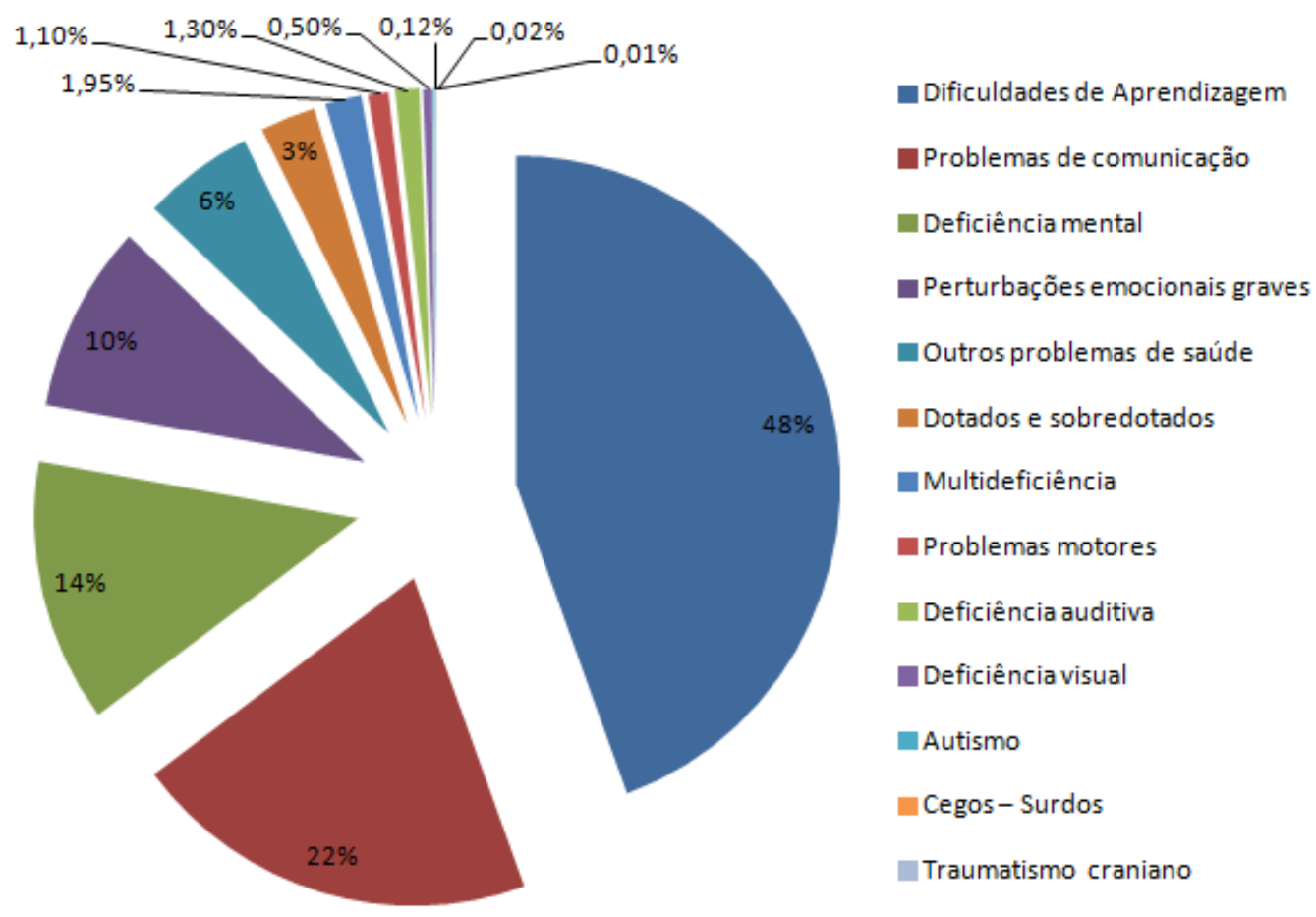

Gráfico 3: O grande grupo das NEE. (Coelho, 2013)

Contudo, a expressão "dificuldades de aprendizagem" pode englobar todas as abrangências que prejudicam um sujeito/pessoa no seu desenvolvimento motor, atrapalhando sua desenvoltura educacional ou de aprendizagem.

Incluir nos Anos Iniciais implica dá respaldo aos sujeitos da aprendizagem, realizando uma reflexão a partir da subjetividade de cada sujeito. Professor e aluno desencadeiam uma relação de confiança, segurança e afetividade nessa primeira etapa da educação básica, por isso, a construção de uma escola para todos deve considerar, também, o papel de cada membro do 
espaço educativo. $\mathrm{O}$ acolhimento requer além do acesso do aluno à escola, independente das suas dificuldades, a permanência destes através de condições plenas de desenvolvimento. Repensar a prática pedagógica como elemento fundamental para a inserção de todas as crianças em escolas regulares, tornou-se uma necessidade real nos últimos anos (LIMA, 2012).

Nesse aspecto, a escola, instrumento criado para libertar os seres humanos da opressão e da alienação tem se configurado como o ambiente ideal para acolher em suas dependências todas as crianças em idade escolar, condição que passou a ser avaliada e repensada em prol da promoção de oportunidades e igualdades. Assim, acolher ou incluir crianças com dificuldades de aprendizagem equivale buscar a plenitude da condição humana (LIMA, 2012).

Atualmente, os debates sobre a inclusão de crianças com DA tornaram-se uma realidade nos âmbitos educacionais de todo o mundo. No entanto, as escolas estão apresentando dificuldades e buscando formas diversificadas para trabalhar com seus alunos. Para tanto, muitas instituições buscam apoio de psicólogos, pedagogos e psicopedagogos para auxiliar suas práticas (LIMA, 2012). Nessa perspectiva, Mantoan ressalta que:

\footnotetext{
A inclusão é produto de uma educação plural, democrática e transgressora. Ela provoca uma crise escolar, ou melhor, uma crise de identidade institucional, que, por sua vez, abala a identidade dos professores e faz com que seja ressignificada a identidade do aluno. $\mathrm{O}$ aluno da escola inclusiva é outro sujeito, que não tem uma identidade fixada em modelos ideais, permanentes, essenciais (MANTOAN, 2003, p. $32)$.
}

As melhores ferramentas para prevenir o insucesso escolar e os melhores indicadores das boas práticas de ensino são o respeito e a valorização da diversidade. Uma escola não pode ser abrangente e inclusiva e, portanto, ser capaz de responder à diferença e à individualidade se toda a comunidade escolar não concorda com esses valores. A diversidade é um princípio fundamental, e não um incidente isolado a ser tratado de forma isolada e residual.

Embora se tenha consciência das complexidades de fatores decorrentes das dificuldades de aprendizagem, segundo Ferreira (2010, p. 70), "serenidade, organização, responsabilidade, trabalho e empenho ajudam a enfrentar os desafios". O psicólogo escolar pode, neste sentido, auxiliar os educadores a terem como foco não a dificuldade, mas a promoção de superação dos limites e desenvolvimento das eficiências, sugerindo metodologias e subsidiando a escolha de recursos pedagógicos para as salas de aulas com alunos que apresentam D.A. ou qualquer outro problema. 
A diversidade é um fato da vida e está presente em cada sujeito, mesmo que este não saiba. Uma escola sem diversidade seria uma instituição asséptica, artificial, desprovida da identidade que se dá pelo reconhecimento da diferença, a marca registrada de cada uma das pessoas que a compõem. Sem diversidade e sem reconhecimento, a escola é órfã de um dos valores fundamentais na educação e formação das pessoas: a tolerância. Cunha (2011) contempla que:

\begin{abstract}
O professor deve criar um clima propício ao aparecimento do desejo e da necessidade de falar, comunicar e de se expressar, desenvolvendo estratégias para que o aluno assuma a linguagem como forma de estruturação do pensamento, veículo de cultura, veículo de sociabilização e meio de comunicação. A criação de um clima de boa compreensão e relação entre professor e alunos e destes entre si é condição indispensável ao aparecimento da vontade de dizer, falar, comunicar. Deste clima faz parte a motivação dos alunos, pois o professor deve partir das suas necessidades, interesses e expectativas (CUNHA, 2011, p.26).
\end{abstract}

O papel da escola consiste em garantir o acesso à educação formal desenvolvendo as potencialidades dos alunos e considerando-os como membros plenos da sociedade. Desse modo, cabe-lhe, também, engajar-se na comunicação e aconselhamento para a família e alunos em seu caminho e trajetória escolar. É, portanto, uma tarefa da escola criar essa cultura de resposta à diferença com a certeza de que é um elemento indispensável e enriquecedor. E isso exige a cumplicidade de todos os membros da comunidade escolar, em que cada um deles assumirá uma parte da tarefa de acolhimento.

Nessa reflexão, Pereira e Gonçalves (2010) propõe a possibilidade de construir um novo paradigma da educação ao enfatizar que:

\begin{abstract}
No ambiente escolar, o professor tem que ser equilibrado emocionalmente, além de dar atenção ao aluno, deve se aproximar, elogiar, saber ouvir e reconhecer seu valor, acreditando na sua capacidade de aprender e de ser uma pessoa melhor. Essas ações favorecem a afetividade no aluno. O professor proporciona segurança e respeito, na forma de expressar seus sentimentos. O carinho e a atenção é parte da trajetória na construção da aprendizagem mútua, sendo apenas o começo do caminho a ser percorrido pelo aluno no período de escolarização. (PEREIRA e GONÇALVES, 2010, p.14).
\end{abstract}

Nesse caso, é muito importante o papel do professor, pois ele deve administrar bem essa situação, de maneira que não haja discriminação, propondo brincadeiras que ajude na socialização e atividades em grupo para que todas as crianças percebam seu papel social. Deve também evitar que as crianças que apresentam dificuldades, não se sintam menosprezadas e retraídas, pelo contrário, mostrar-lhes seus aspectos positivos e do que elas são capazes. 
Promover a socialização destas crianças disgráficas, disortográficas, disléxicas, requer paciência e compromisso, de maneira que não haja a insatisfação da criança, dos colegas e dos próprios educadores (COELHO, 2013).

Ferreira (2010) defende a importância da Psicologia na área educacional dizendo que:

(...) a Psicologia, mediante as intervenções psicopedagógicas, muito pode contribuir para o desenvolvimento não só educacional, mas do ser humano como um todo, com suas técnicas e parcerias que se unem a favor do outro. É necessário aceitar que cada sujeito tenha sua construção social, cultural e uma história de vida. O importante é sermos éticos e trabalharmos em função do outro. (FERREIRA, 2010,p.71).

Para os psicólogos o aprendizado visa ao desenvolvimento cognitivo, intelectual, afetivo, social e ao aprimoramento do potencial humano, considerando que cada indivíduo tem seu tempo e sua forma para desenvolver todos esses aspectos. Sendo assim, o psicólogo deve olhar para as pessoas com respeito e sempre acreditar que todos são capazes de aprender, melhorar, mudar, ao mesmo tempo, compreender o limite de cada um (FERREIRA, 2010).

De acordo com o exposto, percebe-se, então, que a conscientização apresenta-se como fundamental para a difusão de informações a partir de medidas como a promoção de eventos ou projetos dentro das escolas que esclareçam à priori, a problemática da DA, para que somente a partir daí seja feita a correta identificação dos déficits e formulação ou reformulação de técnicas metodológicas específicas para serem aplicadas dentro das escolas.

\section{A Psicologia Escolar e a Intervenção na Vida de Alunos com Dificuldades de Aprendizagem}

A psicologia escolar é uma área abordada com muita frequência recentemente dentro do campo da Psicologia, visto que há necessidade de uma relação dinâmica e aprofundada entre o psicólogo e a escola através de uma intermediação centrada na parceria e na confiança que pode favorecer a aprendizagem e solucionar problemas como os transtornos de aprendizagem. Compreendendo a importância da intermediação entre o psicólogo e a escola para melhor desenvolvimento dos seus alunos, torna-se necessário observar alguns princípios básicos que regem a educação de acordo com a Lei de Diretrizes e Bases da Educação Nacional (Lei 9394/96), a qual assegura que a escola é responsável pela elaboração e a execução da proposta pedagógica que orienta suas responsabilidades durante o ano em vigor, permitindo a 
manutenção de suas normas já estabelecidas e as do sistema educacional em sua complexidade (BRASIL, 1996).

Por esse entendimento, cabe destacar que a emancipação tratada pela psicologia como algo precisa e útil no interior das escolas ressalta a importância de se compreender o fenômeno educacional em sua dinamicidade como produto das relações que se estabelecem no interior da escola, os quais envolvem um pensar reflexivo e inclusivo dos fatores determinantes que regem as decisões escolares, lembrando que esta é atravessada por políticas educacionais e pela história local que influenciam constantemente o desenrolar do planejamento educacional e a vida dos discentes.

Nesse contexto, Sant'Ana e Guzzo (2016) destacam que esses sujeitos podem colaborar com a escola ofertando suas participações nos conselhos escolares e envolvendo-se com as atividades a serem desenvolvidas almejando um ensino/aprendizagem de qualidade. Essa busca incessante por um ensino dinamizador e embasado na interação mútua e eficaz torna-se cada vez mais solícita e válida. Neste mesmo viés, Wanderer e Petroza (2010) enfatizam que suas participações contribuem para a elaboração conjunta de um projeto político-pedagógico onde a figura do psicólogo exerça uma contribuição na resolução dos conflitos existentes no meio escolar colaborando para que as emoções sejam melhores compreendidas e internalizadas no cotidiano do ambiente educativo.

A participação do psicólogo não se resume, apenas, aos interesses internos das instituições, mas abrange todos os sujeitos envolvidos e compromissados com uma educação libertadora e inclusiva. Essa compreensão atenta para o fato de que é preciso considerar o que educadores, gestores, equipe técnica, psicólogos e demais profissionais têm a oferecer na troca de experiências e aprendizados que movem o fazer e refazer das relações escolares.

Para Aquino et al (2015), o saber formal adquirido e que auxilia os indivíduos em sua vida como um todo, se dá mediante a interação entre educando e educador através do desenvolvimento de relações de troca. Essas relações são, também, movidas por afetividade, confiança e aproximação entre os sujeitos, podendo proporcionar transformações na forma de pensar e agir dessas pessoas dando-lhes oportunidades para crescer e desenvolver-se. Desse modo, o psicólogo pode assessorar os trabalhos educacionais dando subsídio aos educadores através do acompanhamento e do desenvolvimento e evolução dos sujeitos que compõe a comunidade escolar. 
Já para Martinez (2003), o psicólogo pode participar da realização de projetos que demandem habilidades específicas do psicólogo apropriando-se de conhecimentos inerentes à profissão. A participação efetiva na formação continuada dos professores, também, é eficaz, uma vez que o preparo e conscientização devem articular-se na ação pedagógica, preparando os mesmos para lidar com as dificuldades e promover a inclusão escolar.

Em concordância com Guzzo (2005) que acredita que o psicólogo pode direcionar sua prática para as individualidades do sujeito, visando favorecer o autoconhecimento e a autonomia dos discentes de modo a alcançar a melhoria das práticas pedagógicas e o favorecimento da autoestima, acredita-se que a atuação do psicólogo escolar nos casos de alunos com D.A. é fundamental, visto que tem a técnica para trabalhar com os aspectos intelectuais do estudante, podendo facilitar seu convívio com sua dificuldade, reconhecendo se num meio social em que cada um possui as suas particularidades e até deficiências e todos podem ser tratados igualmente.

Neste contexto, compreende-se a Psicologia escolar como altamente relevante para auxiliar os docentes e todo corpo escolar em estabelecimentos de metas e metodologias inclusivas que possibilitem aos alunos uma aprendizagem qualificada e beneficente. Além disso, o psicólogo escolar pode atuar em conjunto com as famílias dos alunos com DA (Dificuldades de Aprendizagem), objetivando em todos os sentidos o bem estar e aprendizagem de todos os indivíduos, promovendo a inclusão, o exercício dos direitos iguais e a qualidade do ensino.

\section{Considerações Finais}

Diante do exposto, acredita-se que a inclusão como direito se apresenta, hoje, como necessária. No entanto, na prática continua distante da teoria. É preciso pensar numa reestrutura básica que alcance toda a comunidade escolar, organizando e ampliando o ambiente educativo, no intuito de torná-lo um lugar que

inclua todos os alunos, celebre as diferenças, apoie a aprendizagem e responda as necessidades individuais e conjuntas das crianças.

Neste sentido, compreende-se que em meio aos problemas de aprendizagem, a principal causa é a distração ou falta de atenção durante a execução das atividades, por isso é que se 
encontram nas salas de aula tantos educandos com dificuldades de assimilar os conhecimentos. No entanto, cabe ao professor investigar porque essas coisas acontecem com seus alunos, e, imediatamente procurar maneiras de prender a atenção de seus alunos naquilo que realmente interessa através de metodologias direcionadas para cada particularidade. De certo que, essas dificuldades recebem muitas vezes, o nome de distúrbios, todavia, isso não quer dizer que as crianças sejam perturbadas, tampouco tenham problemas mentais ou incapacidades. Cabe aos seus responsáveis procurar ajuda de profissionais capacitados para que seja iniciado o tratamento o quanto antes.

Quanto à atuação do psicólogo no que se refere às DAs, ele não somente é capaz de lidar adequadamente com a dificuldade apresentada pela criança, como também precisa auxiliar os professores, pedagogos e a família elucidando quais as características, funções, causas e possíveis consequências da determinada dificuldade na vida da criança portadora de DA. Provavelmente, quando essa equipe se dedicar em promover condições para a superação das dificuldades, haverá uma possibilidade maior de que as crianças não carregarão rótulos e não terão seu futuro marcado pelas Dificuldades de Aprendizagem.

\section{Referências}

AQUINO, L, C, G, Concepções e práticas de psicólogos escolares junto a docentes de escolas públicas. In: Revista Quadrimestral da Associação Brasileira de Psicologia Escolar e Educacional, SP. volume 19, Número 1, Janeiro/Abril de 2015: 71-78.

BRASIL. Ministério da Educação. Lei no 9.394, de 20 de dezembro de 1996. Estabelece as diretrizes e bases da educação nacional. Artigo 80. O Poder Público incentivará o desenvolvimento e a veiculação de programas de ensino a distância, em todos os níveis e modalidades de ensino, e de educação continuada. Disponível em:http://portal.mec.gov.br/seed/arquivos/pdf/tvescola/leis/lein9394.pdf. Acesso em: 10 fev. 2018.

COELHO, Diana Tereso. Dificuldades de aprendizagem específicas: Dislexia, Disgrafia, Disortografia e Discalculia. Porto, Areal Editores, 2013 (224 p.).

CUNHA, Sandra Margarida Sousa e. A aprendizagem da leitura e da escrita fatores pedagógicos e cognitivos. Lisboa, 2011.

DÍAZ, Félix. O processo de aprendizagem e seus transtornos. Salvador, EDUFBA, 2011. 
FERREIRA, A. da S.; PACHECO, A. B. Intervenção psicopedagógica numa perspectiva multidisciplinar: trabalhando para o desenvolvimento das potencialidades de estudantes adolescentes. p. 53 à 76. Conselho Federal de Psicologia. Experiências profissionais na construção de processos educativos na escola. Conselho Federal de Psicologia - Brasília: CFP, 2010. $180 \quad$ p. $\quad$ Disponível em:<http://site.cfp.org.br/wpcontent/uploads /2010/09/Construcao_de_processos_educativos_publicacao.pdf . Acesso em: $14 \mathrm{fev}$ de 2018.

GUZZO, R. S. Escola amordaçada: compromisso do psicólogo com esse contexto. In A. Martínez (Org.). Psicologia escolar e compromisso social. Campinas, SP: Alínea, 2005.

LDB. Lei de diretrizes e bases da educação nacional. Lei no 9.394, de 20 de dezembro de 1996. Câmara dos Deputados, Edições Câmara, 9ª ed. Brasília, 2014.

LIMA, Vanda Moreira Machado. A complexidade da docência nos anos iniciais na escola pública. Nuances: estudos sobre Educação, Presidente Prudente, SP, v. 22, n. 23, p. 148-166, maio/ago. 2012.

MARTÍN, P. S.; GONZÁLEZ-GIL, F. Experiências de inclusão na formação de professores. In: RODRIGUES, D. (Org.). Educação inclusiva: dos conceitos às práticas de formação. Tradução de Joaquim Colôa Dias, Maria Bibiana Magalhães, David Rodrigues. Lisboa: Instituto Piaget, 2011. p. 149-155.

MARTÍNEZ, A. M. O psicólogo na construção pedagógica da escola: áreas de atuação e desafios para a formação. In S. Almeida (Org.). Psicologia escolar: ética e competências na formação e atuação profissional (pp. 105-124). Campinas, SP: Alínea, 2003.

MANTOAN, Maria Teresa Eglér. Inclusão escolar: o quê? Por quê? Como fazer?. São Paulo: Moderna, 2003.

PEREIRA, Maria José de Araújo; GONÇALVES, Renata. Afetividade: Caminho para a Aprendizagem. 2010. Disponível em:

<Http://www.seer.unirio.br/index.php/alcance/article/viewFile/669/625> Acesso em 01 Jan.2018.

SANT'ANA, I. M; GUZZO, R. S. L. Psicologia escolar e projeto político-pedagógico: Análise de uma experiência. In: Psicologia \& Sociedade, v. 28 n. 1, 194-204, 2016.

SANTOS, Euzila Pereira dos. Dificuldades de Aprendizagem nas Séries Iniciais do Ensino Fundamental. Goiás - GO.73 páginas. Faculdade de Educação - FE. Universidade de Brasília - UnB. 2015.

WANDERER, A; PEDROZA, R. Elaboração de projetos político-pedagógicos: reflexões acerca da atuação do psicólogo na escola. Psicologia Escolar e Educacional.14(1), 121-129. 2010.

Como citar este artigo (Formato ABNT): 
SILVA, Byanca E. D.; MOREIRA, Henry W.D.; OLIVEIRA, Andreia B de; SILVA, Maria Auxiliadora L.; CARVALHO, Maria das Graças de. Contribuições do Psicólogo Escolar no Processo de Inclusão de Crianças com Dificuldades de Aprendizagem na Escola. Id on Line Rev.Mult. Psic., 2018, vol.12, n.40, p.214-227. ISSN: 1981-1179.

Recebido: $12 / 03 / 2018$

Aceito 14/03/2018 